\title{
Pengaruh mobilisasi dan rangsangan taktil secara bersamaan terhadap pemulihan motorik anggota gerak atas pada pasien stroke
}

\author{
Susanto \\ Leonard S. Angliadi \\ Program Studi Ilmu Kedokteran Fisik dan Rehabilitasi Fakultas Kedokteran \\ Universitas Sam Ratulangi - RSUP Prof. Dr. R. D. Kandou Manado \\ Email: santomd11274@gmail.com
}

\begin{abstract}
Rehabilitation evaluation belongs to functional evaluation. Function of hand can be measured by action research arm test (ARA) and motricity index. This study was aimed to obtain the effects of mobilization and tactile stimulation on motoric recovery of upper extremity in stroke patients. This was an experimental study with a pretest-posttest design. This study was conducted at the Departement of Medical Rehabilitation Prof. Dr. R. D. Kandou Hospital Manado from May to July 2012. Subjects were stroke patients (males and females). Each patient was treated with mobilization and tactile stimulation at the same time. Effects of mobilization and tactile stimulation on motoric recovery of upper extremity were evaluated by using ARA test and motricity index. There were 18 stroke patients (males and females) with an average age of 53.9 years old in this study. The Wilcoxon signed rank test showed significant differences between the end result and the initial value of ARA test $(P=$ $0.0001)$ as well as of the motricity index $(P=0.0001)$. Conclusion: There was increased motoric recovery of upper extremities in stroke patients after treatment with mobilization and tactile stimulation.
\end{abstract}

Keywords: stroke, upper extremity, motoric recovery, rehabilitation

\begin{abstract}
Abstrak: Evaluasi rehabilitasi tergolong dalam evaluasi fungsi. Tingkat fungsi tangan dapat dinilai dengan menggunakan action research arm test (ARA) dan motricity index. Penelitian ini bertujuan untuk mengetahui pengaruh mobilisasi dan rangsangan taktil terhadap pemulihan motorik anggota gerak atas pada pasien stroke. Jenis penelitian ialah eksperimental dengan Pretest-Posttest design. Penelitian dilaksanakan di Instalasi/SMF Rehabilitasi Medik BLU RSUP Prof. Dr. R. D. Kandou Manado sejak bulan Mei hingga Juli 2012. Subyek penelitian ialah pasien stroke baik laki-laki maupun perempuan. Setiap pasien diberikan mobilisasi dan rangsangan taktil secara bersamaan. Pengaruh mobilisasi dan rangsangan taktil secara bersamaan terhadap pemulihan motorik anggota gerak atas dinilai dengan menggunakan tes ARA dan motricity index. Hasil penelitian mendapatkan 18 pasien stroke laki-laki dan perempuan dengan rerata usia 53,9 tahun. Hasil tes uji Wilcoxon signed ranks mendapatkan adanya perbedaan sangat bermakna dari hasil akhir dan awal baik tes ARA $(P=0,0001)$ maupun motricity index $(P=0,0001)$. Simpulan: Terdapat peningkatan pemulihan motorik ekstremitas atas pada pasien stroke setelah mendapat intervensi berupa mobilisasi dan rangsangan taktil secara bersamaan.
\end{abstract}

Kata kunci: stroke, anggota gerak atas, pemulihan motorik, rehabilitasi

Menurut definisi dari WHO tahun 1986 stroke adalah suatu gangguan fungsional otak yang terjadi secara mendadak dengan tanda dan gejala klinis fokal maupun global yang berlangsung lebih dari 24 jam atau dapat menimbulkan kematian tanpa adanya penyebab lain yang jelas selain vaskular. ${ }^{1}$

Di Sulawesi Utara jumlah penderita 
stroke pada 4 rumah sakit dalam periode 1999-2001 sebanyak $2.780(2,01 \%)$ dari 138.112 total penderita rawat inap. Dari 2.700 penderita stroke akut yang dirawat terdapat $545(19,6 \%)$ dengan stroke akut yang fatal. ${ }^{1}$ Di Instalasi Rehahabilitasi Medik BLU RSUP Prof. Dr. R. D. Kandou Manado pada tahun 2011 untuk kasus stroke terdapat sebanyak 468 pasien dari jumlah pasien baru sebesar 1.673 yang mencakup $27,9 \%$ dari seluruh kasus yang ada. $^{2}$

Diagnosis stroke dan diagnosis bandingnya ditentukan berdasarkan pada anamnesis, pemeriksaan fisik umum, pemeriksaan neurologik, dan pemeriksaan penunjang. Anamnesis tentang riwayat penyakit dahulu dapat membantu identifikasi faktor risiko stroke. Pemeriksaan fisik termasuk pemeriksaan medis umum dan pemeriksaan neurologik. ${ }^{3}$

Prognosis pemulihan fungsional anggota gerak atas sangat bervariasi. Umumnya prognosis dikatakan buruk bila terdapat paralisis total pada saat onset atau tidak adanya grasp yang dapat terukur dalam waktu 4 minggu. Berg dan Hirsberg menyatakan bahwa jika tidak ada gerakan awal yang terjadi dalam 3 bulan pertama maka prognosis pemulihan dikatakan buruk. ${ }^{4,5}$

Pada kasus stroke yang mengenai arteri serebri media, anggota gerak atas lebih banyak terlibat dibandingkan anggota gerak bawah dan pemulihan yang terjadi umumnya tidak lengkap. Menurut Twitchell, bila anggota gerak atas lebih buruk dibanding anggota gerak bawah saat onset maka waktu kembalinya gerakan tangan merupakan prediksi terpenting untuk pemulihan fungsional anggota gerak atas. ${ }^{5}$

Pemulihan klinis fungsi setelah kerusakan atau cedera pada susunan saraf pusat (SSP) ini dapat terjadi dalam waktu beberapa jam atau hari setelah onset atau dapat dimulai dan terus berlangsung selama berbulan-bulan. ${ }^{6}$ Menurut acuan pustaka lain sebagian besar pemulihan terjadi dalam 3 sampai 6 bulan pertama setelah onset atau menurut Skillbeck (1983) dan Richards et al. (1992) serta Jorgensen (1995), terjadi pemulihan yang berlangsung dengan lambat sampai sekitar 6 bulan onset $^{7}$ dan sesudah itu hanya terjadi sedikit perbaikan yang dapat diukur. Walaupun demikian terdapat sejumlah pasien mengalami perbaikan parsial signifikan dari gerakan volunter yang dapat terus berlanjut sampai rentang waktu lebih panjang. ${ }^{8}$ Pendapat lain menyatakan bahwa pemulihan paling besar terjadi pada 6 minggu pertama onset stroke dan tindakan rehabilitasi meningkatkan pemulihan alami tersebut. Namun demikian sejumlah studi intervensi pada stroke kronis menegaskan bahwa pemulihan fungsional dan perubahan otak dapat terjadi lebih dari 6 bulan setelah stroke, ${ }^{9}$ bahkan dari hasil penelitian menunjukkan bahwa pemulihan fungsional akibat stroke dapat terus berlangsung selama beberapa bulan sampai tahunan.

Pemulihan motoris anggota gerak atas dapat terjadi oleh karena pemberian latihan seperti mobilisasi dan rangsangan taktil. Mobilisasi adalah suatu pergerakan yang dihasilkan dari perubahan posisi tubuh atau perpindahan lokasi. Mobilisasi yang digunakan dibantu dengan masase, stretching, gerakan pasif sendi, dan gerakan aktif dibantu. Untuk rangsangan taktil yang diberikan yaitu menggosok kulit daerah anggota gerak atas dengan sikat yang dilakukan berulang-ulang. Pemulihan anggota gerak atas pada subyek penelitian yang dinilai dengan melihat adanya perubahan pada pemulihan dalam fungsi motorik halus grasp (menggenggam), grips (memegang dengan cara mencengkram), pinch (menjepit/mencubit) dan fungsi motoris kasar (gross motoric). ${ }^{10}$ Penilaian berapa besar perubahan pemulihan motoris yang terjadi pada subyek penelitian dinilai dengan tes ARA dan motricity index..$^{10,11}$

Tujuan penelitian ini ialah untuk mengetahui pengaruh mobilisasi dan rangsangan taktil secara bersamaan terhadap pemulihan motoris anggota gerak atas yang mengalami kelemahan pada penderita stroke. 


\section{METODE PENELITIAN}

Jenis penelitian ini ialah eksperimental dengan pretest-posttest design. Penelitian dilaksanakan di Instalasi Rehabilitasi Medik BLU RSUP Prof. Dr. R. D. Kandou, Manado dan waktu penelitian dimulai 1 Mei sampai dengan 31 Juli 2012.

Subyek penelitian ialah pasien yang mengalami stroke baik yang dirujuk maupun datang sendiri ke Instalasi Rehabilitasi Medik BLU RSUP Prof. Dr. R. D. Kandou yang memenuhi kriteria. Kriteria penerimaan ialah pasien yang mengalami stroke lebih dari 3 bulan; usia 45-70 tahun; keadaan umum stabil untuk mengikuti protokol tes dan intervensi; kekuatan otot pada anggota gerak atas < 3; spastisitas otot menurut Modified Ashworth Scale <2; MMSE skor $\geq 24$; skor depresi menurut Becks Depresion Scale <30; dan bersedia mengikuti penelitian dengan menandatangani persetujuan (informed consent). Kriteria penolakan ialah adanya gangguan komunikasi, tidak kooperatif, tidak memahami dan mengikuti perintah, serta ditemukan fraktur, luksasi, dan nyeri pada anggota gerak atas yang lemah. Kriteria gugur bila penderita melakukan terapi kurang dari 15 kali dari 18 kali latihan yang dijadwalkan dan/atau tidak melakukan terapi 3 kali berturut-turut.

Subyek dinilai dengan tes ARA dan motricity index disertai penilaian untuk kekuatan otot, tonus otot, Mini Mental State Examination, dan Becks Depression Inventory. Setelah semua hal tersebut dilakukan maka subyek diberikan intervensi dengan mobilisasi secara bertahap dan diberikan rangsangan taktil dengan waktu maksimum 60 menit setiap hari pada anggota gerak yang mengalami kelemahan selama 6 minggu. Setiap sesi dicatat terapi yang diberikan secara rinci sesuai jadwal penanganan. Subyek yang telah selesai menjalankan program akan dievaluasi kembali dengan tes ARA dan motricity index arm section.

\section{HASIL PENELITIAN}

Hasil penilaian tes ARA pada semua subyek dapat dilihat pada Tabel 1 sednagkan hasil penilaian motricity index (arm section) pada semua subyek dapat dilihat pada Tabel 2.

Hasil uji kenormalan data dengan uji Kolmogorov-Smirnov diperoleh hasil sebagai berikut:

1. Data hasil tes ARA di awal menyatakan data tidak menyebar normal $(P<0,05)$,

2. Data hasil tes ARA di akhir menyatakan data menyebar normal $(P>0,05)$,

3. Data hasil motricity index di awal menyatakan data tidak menyebar normal $(P<0,05)$,

4. Data hasil motricity index di akhir menyatakan data menyebar normal $(P<$ $0,05)$

Oleh karena data hasil tes ARA awal dan motricity awal tidak menyebar normal maka uji perbedaan hasil tes awal dan akhir pada kedua alat tes (ARA dan motricity) diuji dengan uji Wilcoxon Signed Ranks yang menyatakan terdapat perbedaan sangat bermakna antara hasil akhir dan awal tes ARA $(P=0,0001)$, dan perbedaan sangat bermakna antara hasil akhir dan awal motricity index $(P=0,0001)$.

\section{BAHASAN}

ARA test banyak digunakan dalam studi penelitian terutama untuk mengukur fungsi anggota gerak atas bagian distal. ${ }^{10}$ Pada penelitian ini semua subyek diminta melakukan semua tahapan pada tes ARA untuk menguji keterbatasan fungsi tangannya. Hasil penelitian ini menunjukkan peningkatan skor rata-rata tes ARA dari fase awal sampai fase intervensi sebesar 10 poin yaitu 4,67 sampai dengan 14,67.

Morticity index digunakan untuk mengukur kekuatan motorik ekstremitas pada pasien stroke. ${ }^{11}$ Pada penelitian ini semua subyek diminta untuk melakukan semua tahapan yang ada pada morticity index (bagian ekstremitas atas saja). Ditemukan adanya peningkatan skor ratarata morticity index (arm section) dari ratarata fase awal yaitu 20,78 dan fase setelah intervensi yaitu rata-rata fase akhir 47,11. 
Tabel 1. Hasil Penilaian ARA

\begin{tabular}{lccccc}
\hline Tes ARA & Minimum & Maksimum & Rata-rata & $\begin{array}{c}\text { Simpangan } \\
\text { baku }\end{array}$ & Median \\
\hline Awal & 1,00 & 29,00 & 4,67 & 6,834 & 2,00 \\
Akhir & 1,00 & 51,00 & 14,67 & 12,409 & 11,00 \\
\hline
\end{tabular}

Tabel 2. Hasil Penilaian Motricity index (arm section)

\begin{tabular}{lccccc}
\hline $\begin{array}{l}\text { Morticity index } \\
\text { (arm section) }\end{array}$ & Minimum & Maksimum & Rata-rata & $\begin{array}{c}\text { Simpangan } \\
\text { baku }\end{array}$ & Median \\
\hline Awal & 9,00 & 60,00 & 20,77 & 14,002 & 18,00 \\
Akhir & 18,00 & 83,00 & 47,11 & 21,342 & 47,00 \\
\hline
\end{tabular}

Tabel 3. Hasil analisis perbedaan tes ARA dengan Uji Wilcoxon Signed Ranks

\begin{tabular}{cccc}
\hline Tes ARA & Median & Nilai $\mathbf{Z}$ & Nilai $\boldsymbol{P}$ \\
\hline Sebelum & 2,0 & $-3,521$ & 0,0001 \\
Sesudah & 11,0 & & \\
\hline
\end{tabular}

Tabel 4. Hasil analisis perbedaan motricity index dengan Uji Wilcoxon Signed Ranks

\begin{tabular}{lrrr}
\hline Motricity index & Median & Nilai Z & \multicolumn{1}{c}{ Nilai $\boldsymbol{P}$} \\
\hline Sebelum & 18,0 & $-3,729$ & 0,0001 \\
Sesudah & 47,0 & & \\
\hline
\end{tabular}

Hasil penelitian ini membuktikan adanya pengaruh mobilisasi dan rangsangan taktil pada lengan dan tangan terhadap pemulihan motorik eksremitas penderita stroke. Hal ini terlihat jelas dari peningkatan skor tes ARA dan morticity index (arm section) antara fase awal dan fase akhir setelah mengalami intervensi selama 6 minggu dengan mendapat penanganan mobilisasi dan rangsangan taktil secara bersamaan pada ekstremitas atas yang paresis $(P<0,001)$.

Pemulihan motorik terjadi melalui dua mekanisme utama yaitu: 1) resolusi dari faktor-faktor lokal yang merusak dan hal ini biasanya merupakan pemulihan spontan yang umumnya berlangsung antara 3 sampai dengan 6 bulan, bahkan proses ini bisa hanya dalam beberapa hari sampai beberapa minggu. Proses ini meliputi pengurangan edema lokal, perbaikan sirkulasi darah lokal dan penyerapan jaringan yang rusak; 2) Neuroplastisitas yang terjadi pada stadium lanjut. Penderita stroke mempunyai hubungan bermakna dengan reorganisasi yang disebut neuroplastisitas dalam proses perbaikan sistem saraf. Dengan neuroplastisitas, otak mempunyai kemampuan untuk beradaptasi, memperbaiki, dan mengatasi perubahan lingkungannya melalui berbagai cara yaitu: ${ }^{5}$

1. Sprouting (collateral sprouting) merupakan respon neuron daerah yang tidak mengalami cedera dari sel-sel yang utuh ke daerah yang denervasi setelah adanya cedera. Perbaikan fungsi SSP dapat berlangsung beberapa bulan atau tahun setelah cedera dan dapat terjadi secara luas di otak pada daerah nukleus, hipokampus dan sistem saraf tepi.

2. Unmasking: Dalam keadaan normal, banyak akson dan sinaps yang tidak aktif. Apabila jalur utama mengalami kerusakan maka fungsinya akan diambil oleh akson dan sinaps lainnya menurut 
Wall dan Kabath

3. Diachisia (dissipation of diachisia) yaitu keadaan dimana terdapat hilangnya kesinambungan fungsi atau adanya hambatan fungsi dari traktus-traktus sentral di otak.

Perbaikan fungsi pada penderita pasca stroke dapat dilakukan melalui dua cara yaitu: ${ }^{12}$

1. Latihan gerak atau mobilisasi dini untuk memengaruhi fungsi otot pada sisi anggota gerak yang mengalami kelemahan

2. Latihan untuk memengaruhi gerak kompensasi sebagai pengganti daerah yang akan mengalami kelemahan.

Rangsangan taktil pada prinsipnya harus menimbulkan kontraksi otot, sehingga akan merangsang muscle spindle dan Golgi tendon. Impuls yang berasal dari kedua organ tersebut dikirim oleh serat konduksi bermielin yaitu serat Ia. Impuls propioseptif lain yang berasal dari reseptor fasia, sendi, dan jaringan ikat yang lebih dalam, juga dalam serat yang kurang bermielin. Rangsangan taktil akan merangsang propioseptor pada kulit dan persendian, serta muscle spindle yang akan bereaksi dengan dikirimnya impuls ke motoneuron anterior. Perangsangan neuron ini menyebabkan peningkatan kontraksi secara singkat. Rangsangan pada muscle spindle dan Golgi tendon akan diinformasikan melalui serta saraf aferen ke susunan saraf pusat sehingga akan mengkontribusikan fasilitasi dan inhibisi. Rangsangan taktil yang diulang-ulang akan memberikan informasi ke mekanisme supraspinal sehingga terjadi pola gerak yang terintegrasi dan menjadi gerakan-gerakan pola fungsional. ${ }^{13}$

Mobilisasi dan rangsangan taktil secara bersamaan mderupakan intervensi terapi yang tepat dan efektif yang berpotensi untuk memulai proses pengaktivasian otot pada stroke dengan memberikan informasi proprioseptif dan somatosensoris yang signifikan pada otak, serta memfasilitasi langsung aktivasi korteks motorik primer dan sistem kortikospinal untuk meningkatkan aktivasi motorik. ${ }^{13}$

\section{SIMPULAN}

Dari hasil penelitian dan bahasan dapat disimpulkan bahwa terdapat perbedaan yang sangat bermakna antara hasil akhir dengan hasil awal tes ARA dan morticity index yang menunjukkan adanya peningkatan pemulihan motorik ekstremitas atas pada pasien stroke setelah mendapat intervensi berupa mobilisasi dan rangsangan taktil secara bersamaan.

\section{SARAN}

Upaya meningkatkan pemulihan motoris anggota gerak atas pada penderita stroke dapat dilakukan dengan cara memberikan mobilitas dan rangsangan taktil. Disarankan bagi pasien stroke yang datang berobat ke Poliklinik Rehabilitasi Medik BLU-RSUP Prof Dr. R. D. Kandou dapat diberikan mobilisasi dan rangsangan taktil untuk pemulihan motoris anggota gerak atas.

\section{DAFTAR PUSTAKA}

1. Bartels M. Patophysiology and medical management of stroke. In: Gillem G, Burkhardt A, editors. Stroke Rehabilitation. A function - based approach (1st ed). St Louis: Mosby, 1998: p. 1-46.

2. Data statistik kunjungan pasien di Instalasi Rehabilitasi Medik BLU RSUP Prof. Dr. R. D. Kandou Manado 2008-2012.

3. Radomski MV, Trombly CA. Neurophysiological and development treatment approaches. In: Trombly CA, editor. Occupational Theraphy for Physical Dysfunction (2nd ed). Baltimore: William \& Wilkins; p. 73122.

4. Brammer CM, Herring GM. Stroke rehabilitation. In: Brammer CM, editor. Manual of Physical Medicine and Rehabilitation (1st ed). Philadelphia: Hanley \& Belfus Inc, 2001; p. 139-66.

5. Anderson T. Rehabilitation of patients with completed stroke. In: Kottke FJ, editor. 
Krusen's Handbook of Physical Medicine and Rehabilitation (3rd ed). Philadelphia: WB Saunders Company, 1982; p. 583603.

6. Challenor YB, Borkow RB. Central nervous system plasticity and cognitive remeditation. In: Downey JA, Myers SJ, Gonzalea EG, Lieberman JS, editors. The Physiological Basis of Rehabilitation Medicine (2nd ed). Boston: ButterworthHeinemann, 1994; p. 599-624.

7. Ryerson SD. Hemiplegia. In: Umphred DA, editor. Neurological Rehabilitation (4th ed). St Louis: Mosby, 2001; p. 741-86.

8. Brandstater ME. Stroke rehabilitation. In: Delisa JA, editor. Rehabilitation Medicine, Principles and Practice (3rd ed). Philadelphia: Lippincott-Raven, 1998; p. 1165-89.

9. Richards CL, Wood-Dauphinee S, Malouin F. Chapter 4. Outcome measurement: Basic principles and applications in stroke rehabilitation. Textbook of Neural Repair and Rehabilitation. Cambridge University Press, 2014; p. 35-50.

10. Janis J. Patofisiologi stroke iskemik. In: Simposium Stroke Update. Manado, November 2001; p. 33-40.

11. Wade CC. Assessing motor impairment after stroke: a pilot reliability study. J Neurol Nerosurg Psychiatry. 1990;53:576-9.

12. Sheperd $\mathbf{C}$. The adaptive system: plasticity and recovery. In: Sheperd J, editors. Neurological Rehabilitation: Optimizing Motor Performance (1st ed). British: Butterworth-Heinemann, 1998; p. 1-19.

13. Van der Lee JH, De Groot V, Beckerman H, Wagenaar RC, Lankhorst GJ, Bouter LM. The intra and interrater reliability of action research arm test: a practical test of upper extremity function in patients with stroke. J Arch Phys Med Rehabil. 2001;82:14-9. 